\title{
O pensar de ordem superior e o papel do diálogo investigativo no fazer filosofia na educação básica
}

\author{
Altair Alberto Fávero ${ }^{15}$ \\ Junior Bufon Centenaro ${ }^{16}$
}

\begin{abstract}
Resumo: O presente ensaio tem por escopo reconstruir a ideia lipmaniana do pensar de ordem superior, caracterizar o papel do diálogo no processo de fazer filosofia na educação básica e abordar a formação continuada docente como tarefa intrasferível para a possibilidade de êxito na promoção da educação para o pensar. O ensaio é resultado parcial de uma pesquisa bibliográfica, de cunho hermenêutico, vinculada ao projeto Políticas para o Ensino de Filosofia. O texto está organizado em três momentos: inicialmente busca definir o conceito do "pensar de ordem superior"; num segundo momento, a partir de Matthew Lipman (2008), aborda o diálogo investigativo como cerne para o exercício do pensar de ordem superior; por fim, no terceiro momento, trata dos desafios da formação dos professores da educação básica para que possam conduzir seu trabalho numa perspectiva do paradigma crítico-reflexivo da educação para o pensar.
\end{abstract}

Palavras chaves: fazer filosofia; pensar de ordem superior; Lipman.

\section{Higher order thinking and the role of investigative dialogue in doing philosophy at basic education}

\begin{abstract}
The scope of the present essay is to reconstruct the Lipmanian idea of higher order thinking, to characterize the role of dialogue in the process of doing philosophy at

15Doutor em Educação (Ufrgs), Mestre em Filosofia do Conhecimento (Pucrs), Especialista em Epistemologia das Ciências Sociais (UPF) e Graduado em Filosofia (UPF). É coordenador dos Estágios supervisionados do Curso de Filosofia, professor do Corpo docente permanente do Mestrado em Educação atuando na linha de Políticas Educacionais, da Universidade de Passo Fundo. E-mail: favero@upf.br

16Licenciado em Filosofia pela Universidade de Passo Fundo (2016); Pós Graduando em Espiritualidade pela Itepa Faculdades; bolsista pelo subprojeto Filosofia do Programa de Iniciação à Docência (PIBID) desde 2014; participante do grupo de pesquisa \&quot; Interdisciplinaridade, Docência Universitária e Políticas Educacionais\&quot; na Universidade de Passo Fundo; articulador e assessor das Pastorais Sociais da Arquidiocese de Passo Fundo/RS. E-mail: junior.centenaro@bol.com.br

Revista Digital de Ensino de Filosofia - Santa Maria - vol.2., n.2 - jul./dez. 2016.
\end{abstract}


basic education and approach the teacher's continuing education as a nontransferable task for the possibility of success in promotion of education for thinking. The essay is a partial result of a bibliographic research, of hermeneutical nature, linked to the project Policies for the Philosophy Teaching. The text is organized in three moments: initially it seeks to define the concept of "higher order thinking"; in a second moment, from Matthew Lipman (2008), it approaches the investigative dialogue as the core for the exercise of higher order thinking; finally, in the third moment, it deals with the challenges of the formation of basic education teachers so that they can conduct their work in a perspective of the critical-reflective paradigm of education for thinking.

Keywords: to do philosophy; higher order thinking; Lipman.

\section{Introdução}

Em uma de suas principais obras, O Pensar na educação, o filósofo Matthew Lipman (2008), direcionando-se para a crise educacional norte-americana, após a metade do século passado, afirmou metaforicamente que muitos dirão que a cura parece pior que a doença, e que no entanto, estes não observaram o paciente. "O que é certo é que as escolas em toda parte são acusadas porque os conhecimentos dos alunos têm se mostrado muito deficientes, e que o pouco que os alunos sabem é sustentado de maneira quase totalmente acrítica, e o pouco sobre o qual refletem é feito de maneira destituída de imaginação" (2008, p. 44).

Diante disso, consideramos importante situar e destacar alguns pontos fundamentais do pensamento lipmaniano para o ensino de filosofia e para educação de forma geral, pois constamos que vários dos problemas apontados por Lipman num passado não muito distante ainda estão latentes, de modo especial na educação básica do Brasil e nos programas de formação para professores. A escola tem dificuldades em possibilitar aos alunos um papel ativo no processo educacional e grande parte dos professores não estão preparados para tal tarefa. Impera muito a concepção da criança como passiva, como lugar para depositar informações e conhecimentos já definidos. A escola não consegue educar para a investigação e nem para a dimensão participativa da investigação.

Se por um lado é preciso enfrentar um modelo conteudístico de Revista Digital de Ensino de Filosofia - Santa Maria - vol.2., n.2 - jul./dez. 2016. 
educação, que presa apenas pelo conteúdo sem levar em consideração o processo e os sujeitos envolvidos nele, de outro é urgente fazer frente a um modo "espontaneísta" de ensino que vê apenas nos recursos didáticos elementos suficientes para uma educação aprofundada. Esse modo leva a um superficialismo sem precedentes, diante de uma realidade complexa e multifacetada em que se vive. Pretendemos com esse ensaio problematizar e encontrar possíveis respostas ao problema pedagógico de transformar a criança que já pensa numa criança que pensa bem. Como seria a contribuição do ensino de filosofia para isso? Será necessário educadores diferenciados para tal tarefa?

Para tal tarefa, tomamos como referência Matthew Lipman, filósofo norte-amerciano, considerado um divisor de águas com relação ao ensino de Filosofia. Lipman e seus colaboradores, criaram nos anos de 1970, na Universidade de Colúmbia, um Programa de Filosofia para Crianças, com o objetivo de desenvolver habilidades cognitivas, para estimular um pensamento de ordem superior desde as etapas iniciais da escola. A proposta surge diante uma análise minuciosa do sistema educacional de seu tempo, ou seja, boa parte do século XX. Em vista de uma melhor exposição didática, apresentaremos o texto em momentos: Inicialmente buscaremos definir o conceito do "pensar de ordem superior"; num segundo momento abordaremos a partir de uma perspectiva lipmaniana o diálogo investigativo como cerne para o exercício do pensar de ordem superior; por fim, no terceiro momento, trataremos dos desafios da formação dos professores da educação básica para que possam conduzir seu trabalho numa perspectiva do paradigma crítico-reflexivo da educação para o pensar.

\section{Matthew Lipman e a necessidade de um "pensar de ordem superior"}

Para Lipman (2008, p. 28, grifos do autor), existem dois paradigmas em contraste na prática educativa: "o paradigma-padrão da prática normal e o paradigma-reflexivo da prática crítica". Tonieto (2007. p. 20), afirma que, o paradigma-padrão "entende a prática educativa como sendo uma transmissão de conhecimentos que ocorre de maneira assimétrica, ou seja, o Revista Digital de Ensino de Filosofia - Santa Maria - vol.2., n.2 - jul./dez. 2016. 
conhecimento já elaborado é apenas repassado do educador para o educando". Nessa perspectiva, Elias (2005, p. 78), acrescenta que a "atenção é voltada ao conhecimento, o qual, por sua vez, é repassado de geração em geração como um princípio certo e inexaurível". Esse modo, tido como normal, possibilita que "os alunos adquiram conhecimentos por intermédio da absorção de informações, i. é, de dados sobre assuntos específicos" (LIPMAN, 2008, p. 29).

Por outro lado, o paradigma-reflexivo, segundo Lipman (2008, p. 29), entende a educação como "resultado da participação em uma comunidade de investigação orientada pelo professor"; dessa forma os alunos são provocados a pensar sobre o mundo, "entendido como 'complexo', 'problemático' e 'controverso', o que estimula educadores e educandos a pensarem sobre o próprio conhecimento e, sobre suas compreensões de mundo" (TONIETO, 2007, p. 20). O professor, por sua vez, assume uma postura de falibilidade, pronto para admitir erros e equívocos. Nesse modo reflexivo, há uma expectativa maior com relação aos alunos, de que pensem e reflitam, e consequentemente desenvolvam cada vez mais o uso da razão e a capacidade de serem criteriosos. Para o filósofo norte-americano, "o enfoque do processo educativo não é a aquisição de informações, mas sim a percepção das relações contidas nos temas investigados" (LIPMAN, 2008, p. 29).

A crítica lipmaniana é ousada, diante de um contexto educacional, orientado por uma prática padrão, pouco reflexiva, de repetição e de caráter transmissor de conteúdos sem criticidade, criatividade e complexidade. A guinada proporcionada por Lipman torna-se evidente quando afirma que "em vez de conceber a mente como um recipiente passivo e vazio que deve ser preenchido com informações e conteúdos, para ser educado, pressupõe-se que as crianças aprendem ao estarem envolvidas ativamente em uma exploração" (2001, p. 119). O conhecimento não é automaticamente aprendido, como acionar um botão de liga/desliga, mas algo que se apropria por meio da interação com o contexto e na solução de problemas que são importantes para as crianças.

Diante dessa nova configuração, para Elias (2005, p. 79), "deparamonos então, com uma transposição do foco da educação, do informar e Revista Digital de Ensino de Filosofia - Santa Maria - vol.2., n.2 - jul./dez. 2016. 
conhecer, para o aprender a pensar. [...]. Mas, um pensar que possibilite aos alunos mais flexibilidade e desembaraço intelectual". Ao falar em "paradigmas", Lipman sugere que é preciso reestruturar todo o processo educacional saindo de um modo tradicional em direção a um reflexivo-crítico. Como observamos, a proposta lipmaniana é de uma educação para o pensar, que tem como princípio ${ }^{17}$ o diálogo investigativo realizado em comunidade, que se volta para o desenvolvimento do "pensar de ordem superior e de habilidades cognitivas" (TONIETO, 2007, p. 21).

Existe alguma diferença significativa entre "pensar" e "pensar de ordem superior"? Sim, uma enorme diferença. Lipman ajuda a entender que não existe como uma pessoa viva e ativa abandonar o processo de pensar. $\bigcirc$ ato de pensar é constitutivamente natural do ser humano, entretanto pode ser aperfeiçoado, visto que "existem maneiras de pensar mais eficientes e outras menos eficientes" (2014, p. 35). Conceitualmente o pensar de ordem superior é definido como "fusão dos pensamentos crítico e criativo" (2008, p. 38, grifo nosso). Tal modo de pensar, "exige tanto um pensamento flexível como um pensamento rico em recursos, pois é necessário saber onde procurar recursos e ser capaz de lidar com esses recursos, afim de que sejam eficazes" (TONIETO, 2007, p. 24).

Na obra O Pensar na Educação, Lipman define que "o pensamento crítico é um pensar responsável e habilidoso que facilita bons juízos porque se fundamenta em critérios, é autocorretivo e é sensível ao contexto" (2008, p. 172). Nota-se na definição proposta por Lipman a presença de três componentes básicos do pensar crítico. O que caracteriza cada um destes elementos?

Critérios, "são razões; são um tipo de razão, um tipo particularmente confiável. Quando temos que dispor coisas descritivas ou avaliativamente - e estas são duas tarefas muito importantes - temos que fazer uso das razões mais confiáveis que formos capazes de encontrar" (LIPMAN, 2008, p. 173). São definidos como normas para se emitir julgamentos. Disto decorre a inter-

17Segundo Tonieto (2007, p. 21), "o que diferencia a abordagem lipmaniana de diálogo em sala de aula com base no paradigma-reflexivo é que o diálogo não se restringe a uma estratégia, mas é o princípio orientador e possibilitador de todo o processo educacional, deslocando o foco do aprender para o ensinar a pensar". Revista Digital de Ensino de Filosofia - Santa Maria - vol.2., n.2 - jul./dez. 2016. 
relação entre critério e julgamento. Para Lipman (2008, p. 174), "é necessário depositar nossas alegações e opiniões, assim como o restante dos nossos pensamentos, sobre uma base firme como um leito de rocha". Ter bons critérios, imprescindíveis para realizar julgamentos, constitui uma maneira de firmar os pensamentos sobre uma base sólida, que permitirá um pensamento crítico. A autocorreção "cuida para que a criança distancie-se do vício de construir as bases de seu pensamento em indícios carentes de criticidade" (ELIAS, 2005, p. 80). Implica na preocupação com a verdade, com a validade e com o erro do próprio pensamento, tornando o aluno e o professor conscientes deste, para corrigi-lo sempre que necessário. A terceira característica é a sensibilidade ao contexto, ou seja, "extrema sensibilidade à singularidade de casos específicos" (LIPMAN, 2008, p 183).

Em linhas gerais, Lipman define o pensamento criativo, como aquele que "conduz ao julgamento, que é orientado pelo contexto, é autotranscendente e sensível a critérios" (LIPMAN, 2008, p. 279). Isso significa que é um tipo de pensamento imaginativo que busca meios para atingir um fim. A criatividade é imprescindível para buscar saídas aos problemas, e conhecendo-se a solução dos mesmos, é necessária a imaginação para vislumbrar o caminho dessas soluções. Por isso,

\footnotetext{
O pensamento criativo [...] busca alternativas tanto às respostas já disponíveis que venhamos a conhecer por informações quanto às respostas produzidas por nós mesmos. Se chego a alguma conclusão, mesmo julgando bem fundamentada em argumentos sólidos, posso propor-me pensar em conclusões alternativas e em argumentos para elas. Posso, também, pensar em levantar os problemas com formulações diferentes, experimentando, a partir daí, novas hipóteses e, então, experimentar novos argumentos (LORIERI apud ELIAS, 2005, p. 81).
}

Pensar criativamente é não estacionar nas respostas já encontradas, mas continuar construindo e buscando novas e mais pertinentes formulações. De modo geral, podemos afirmar que, tanto o pensamento crítico, como o criativo, possuem como objetivo comum fazer julgamentos. Parafraseando Tonieto (2007), o "pensamento crítico, [...], exige raciocínio e julgamento criativo, do mesmo modo como o pensamento criativo exige habilidade, Revista Digital de Ensino de Filosofia - Santa Maria - vol.2., n.2 - jul./dez. 2016. 
talento e julgamento crítico". É impossível um pensamento crítico sem um julgamento criativo, do mesmo modo que, não há um julgamento criativo sem um pensamento crítico. Percebe-se que "a inter-relação entre ambos justificase na medida em que o pensamento crítico dará os critérios e conceitos que orientarão os julgamentos, ao passo que o pensamento criativo incorporará valores e significados aos julgamentos". (2007, p. 26).

O terceiro elemento constitutivo do pensar de ordem superior é pensamento complexo, que busca conciliar a disparidade entre método com pouco conteúdo e conteúdo com pouco método. Para Lipman, o pensamento complexo "leva em consideração a sua própria metodologia, seus próprios procedimentos, sua própria perspectiva e ponto de vista. Ele inclui pensar sobre seus procedimentos ao mesmo tempo em que pensa sobre seu tema principal" (2008, p. 42, grifos do autor). De forma simples o pensamento poderia relacionar-se unicamente com o procedimento, ou por outro lado, ser unicamente substantivo. Por exemplo, pensar logicamente sobre lógica é totalmente metodológico e procedimental; pensar apenas no conteúdo, sem levar em consideração o procedimento ou metodologia é totalmente substantivo. O pensamento complexo faz a aproximação entre esses dois extremos. Diante disso, Tonieto (2007, p. 26), acrescenta que, o "trabalho em sala de aula é orientado por um método que é vivenciado, não ensinado, e por conteúdos que são buscados, não dados, ambos reavaliados constantemente".

Até aqui, definimos muito brevemente e de forma sintética, os principais elementos do que Lipman entende por pensar de ordem superior. Tão fundamental quanto a questão do que é o pensamento de ordem superior é a questão de como ensiná-lo's. Nosso filósofo indica que "fazer com que os alunos filosofem é um exemplo de como o pensamento de ordem superior pode ser estimulado em uma sala de aula" (LIPMAN, 2008, p. 38).

180 "ensinar a pensar" proposto por Lipman, não pode ser considerado em seu sentido literal, pois daria a ideia de transmitir um jeito de pensar e raciocinar aos alunos, o que estaria em pleno desacordo com sua proposta de um paradigma crítico-reflexivo. 0 autor ao se referir ao "ensinar a pensar" sugere que é preciso estimular para o pensar bem, criar ambiente favorável, desenvolver habilidades cognitivas e assim por diante. Em síntese é tentar responder a questão de como devemos fazer para estimular, incentivar, instigar, propiciar às crianças um pensamento mais elaborado, investigador e abrangente.

Revista Digital de Ensino de Filosofia - Santa Maria - vol.2., n.2 - jul./dez. 2016. 
Nessa mesma perspectiva, para Tonieto (2007, p. 27), "o pensamento de ordem superior deve ser ensinado diretamente em sala de aula, sem maiores rodeios". Mas como? Uma sugestão seria a adoção da filosofia como disciplina nas escolas; outra seria promover o desenvolvimento do pensar de ordem superior em cada disciplina pela abordagem da comunidade de investigação.

Lipman sugere que o pensar de ordem superior deve ser realizado no âmbito da escola, porém como já apontamos, não da maneira do paradigma padrão de transmissão de conhecimentos, mas desde um paradigma crítico reflexivo, utilizando-se dos pressupostos filosóficos, numa comunidade de investigação, como veremos mais adiante, que é o "coração" da proposta lipmaniana do pensar de ordem superior.

\title{
2. Comunidade de investigação como espaço para desenvolver o pensar de ordem superior
}

Lipman propõe a inserção da filosofia desde a educação básica na escola, pois para ele a filosofia tem caráter questionador e investigativo e as crianças compartilham quase que naturalmente desses aspectos. Na obra $\mathrm{O}$ Pensar na Educação, além de esclarecer o que é o pensar de ordem superior e seus componentes, sublinha a necessidade de transformar a sala de aula numa comunidade de investigação.

\begin{abstract}
Podemos falar em converter a sala de aula em uma "comunidade de investigação" na qual os alunos dividem opiniões com respeito, desenvolvem questões a partir das ideias de outros, desafiando-se entre si para fornecer razões e opiniões até então não apoiadas, auxiliarem uns aos outros ao fazer inferências daquilo que foi afirmado e buscar identificar as suposições de cada um (LIPMAN, 2008, p. 31).
\end{abstract}

A expressão "converter", possui uma conotação muito forte e significa mudança radical do modo de pensar e agir. Nesse caso específico, a conversão necessária é a da sala de aula como espaço reprodutor de uma Revista Digital de Ensino de Filosofia - Santa Maria - vol.2., n.2 - jul./dez. 2016. 
educação depositária de conteúdos, para espaço de comunidade de investigação, de discussão coletiva sobre temas filosóficos. Os atos de dividir opiniões com respeito, desenvolver questões, fornecer razões e auxiliar os outros a fazer inferências, sinalizam um percurso para se chegar ao pensar crítico, criativo e complexo.

Para Lipman, "uma comunidade de investigação tenta acompanhar a investigação pelo caminho que esta conduz ao invés de ser limitada pelas linhas divisórias das disciplinas existentes" (2008, p. 31). Portanto, é uma proposta que exige transversalidade, ou seja, todo o processo educacional das crianças, deveria estar orientado e/ou perpassado pelo modo investigativo. A comunidade de investigação, na medida em que cresce no desenvolvimento das habilidades cognitivas, possibilita aos alunos e ao professor "pensar como o processo pensa" (LIPMAN, 2008, p. 32). Isso significa que, a comunidade ganha autonomia e faz com que as discussões fluam de maneira quase natural, pois os integrantes internalizaram os movimentos e os procedimentos da investigação dialógico-filosófica.

Como observamos, Lipman, sugere uma educação diferenciada, que priorize a capacidade de pensar do aluno, ao invés do simples acúmulo de informações desprovidas de sentido e significado. O pensar de ordem superior, na comunidade de investigação, se dá, por meio, do desenvolvimento de habilidades cognitivas, a saber (habilidades de raciocínio, habilidades de investigação, habilidades de formação de conceitos e habilidades de tradução), que contribuem na transição de um modelo educacional tradicional para um crítico reflexivo.

A comunidade, no sentido lipmaniano não é imposta como um modelo acabado e estabelecido, mas algo a ser construído e vivenciado pelos integrantes durante a investigação. Contudo, salienta Tonieto, que "a comunidade, [...], não se sustenta com a ausência de regras, tanto de procedimentos como de investigação; é regrada pela lógica formal e informal, de modo a estabelecer certos princípios orientadores que tornam possível a pesquisa, o questionamento e a investigação" (2007, p. 30). A comunidade de investigação é inter-relacional, necessita que os participantes se expressem, escutem, raciocinem, façam comparações, busquem alternativas e assim por diante. Nesse sentido, nada melhor que aprofundar um Revista Digital de Ensino de Filosofia - Santa Maria - vol.2., n.2 - jul./dez. 2016. 
pouco o papel do "diálogo" nesse processo crítico-reflexivo.

Elias (2005, p. 92), também destaca que, Lipman percebeu "o valor educativo do diálogo para o desenvolvimento do pensamento mais habilidoso. O diálogo enquanto interação sócio linguística, é fundamentalmente importante em todo esse processo". Vale observar que na ótica de Lipman, nem todas as discussões propriamente ditas, podem ser definidas como dialógicas: "devemos saber como distinguir meras discussões de boas discussões e precisamos saber o que é característico das discussões filosóficas" (LIPMAN et al, 2001, p. 154).

O que seria, portanto, uma mera discussão? Nosso filósofo, assinala que este tipo de conversa suscita comentários de vários indivíduos presentes, porém sem um alcance comum mínimo de consenso sobre algo. Para Lipman e seus colaboradores, "os indivíduos"19 podem ter êxito em expressar a perspectiva a partir da qual veem determinado assunto, mas as perspectivas nunca se cruzam de modo a formar partes de algum quadro de referência mais amplo" (2001, p. 155). Nenhuma disciplina, inclusive a filosofia, está livre desse tipo de discussão, que não provoca inter-relações e nem mudanças substanciais nos indivíduos, que permanecem com as mesmas convicções e posturas do início da discussão. Diante disso, a mera discussão não funciona como princípio da comunidade de investigação que tem como objetivo o pensar de ordem superior.

Por outro lado, o que seria uma boa discussão? Para o autor, "uma boa discussão ocorre em qualquer área quando o resultado final marca um progresso definitivo em comparação com as condições que existiam quando começou" (LIPMAN et al, 2001, p. 155). Pode ser um progresso na compreensão, ou no alcance de algum tipo de consenso, ou ainda simplesmente pela formulação do problema que deu origem a discussão. Nas palavras de nosso autor,

[...] uma boa discussão é acumulativa; cada contribuição é com efeito, uma linha de força ou um vetor que converge sobre as outras e é orquestrada com as outras. Se ao final do episódio, chega-se a um acordo ou a um completo desacordo, isso não tem muita

19Lipman faz questão de dizer "indivíduos" e não "participantes", porque a mera discussão afirma apenas o caráter individual das pessoas que estão na conversa.

Revista Digital de Ensino de Filosofia - Santa Maria - vol.2., n.2 - jul./dez. 2016. 
importância; o que importa é que as contribuições de cada participante se relacionem e se reforçam à medida que cada um aprende com o que os outros dizem, e a medida que cada sucessiva contribuição reflete os sucessivos desenvolvimentos de compreensão que aqueles participantes acumularam (LIPMAN et al, 2001, p. 155-156).

As discussões insignificantes ou meras discussões, assim como as boas discussões são um solo fértil para que surjam boas discussões filosóficas. Por outro lado, fica claro, que é preciso clareza de que a mudança para um padrão de diálogo investigativo implica rever a metodologia e a qualidade das discussões, caso contrário, não poderíamos fazer referência ao diálogo investigativo como princípio do pensar excelente. A discussão filosófica, por sua vez, promove raciocínio e instiga cada participante a formular racionalmente seus pontos de vista. É uma discussão dirigida, organizada, com uma metodologia específica, e por isso, Lipman destaca que é preciso haver boa preparação para dirigir uma discussão de tal envergadura:

[...] para dirigir uma discussão filosófica, temos que desenvolver uma sensibilidade para saber que tipo de pergunta é apropriada em cada situação e qual a sequência em que podem ser feitas. [...]. Conseguir com que os estudantes se envolvam num diálogo filosófico é uma arte. E como qualquer arte, um pouco de conhecimento é um pré-requisito - nesse caso, o professor deve saber quando intervir ou não numa discussão (LIPMAN et al, 2001, p. 157).

Até aqui percebemos que o "diálogo" em questão, é o filosófico, este que é o coração pulsante da comunidade de investigação. Para Tonieto, é por meio desse modo de diálogo, "que se torna possível o desenvolvimento de habilidades cognitivas, o desenvolvimento do raciocínio e da capacidade de argumentação regrados pela lógica, assim como a investigação sobre problemas que nos interessam enquanto seres humanos" (2007, p. 31). A comunidade de investigação está sempre atenta aos movimentos e situações de cada participante e também dos movimentos e situações do grupo como um todo. A comunidade investigativa, 
exige concepções de mundo pessoais, uma vez que cada participante é uma individualidade, mas no processo de investigação dialógica é dado um passo além, visto que as individualidades, unidas, pensam coletivamente sobre questões humanas que as atingem enquanto seres particulares e sociais. $O$ individual é colocado em questão em favor de um social, o que possibilita $O$ aprimoramento cognitivo individual, que por sua vez, é refletido no social (TONIETO, 2007, p. 32).

Complementando a ideia do diálogo investigativo, Fávero (2007, p. 49), aponta que, "o diálogo deixa algo dentro de nós e algo fica em nós quando consegue nos transformar, ou seja, experienciamos algo novo que nos veio pelo encontro com o outro e que ainda não havíamos encontrado em nossa experiência de mundo". A comunidade de investigação, "pode se constituir num lugar de livre expressão, do pensar partilhado e da construção da autocompreensão ética de cada criança, adolescente e jovem" (FÁVERO, 2007, p. 52). Por fim, ainda em acordo com Fávero (2007, p. 53), "no confronto de ideias, aprendemos a pensar num patamar superior, atingindo, assim, um nível que nos permite desenvolver um pensar mais cuidadoso, criterioso, crítico e criativo".

\section{Crise educacional, formação continuada e educação para o pensar}

Em um belo texto escrito em 1954, intitulado "A crise da educação" e publicado posteriormente na obra Entre o passado e o futuro, Hannah Arendt (2003) analisa a crise da educação na sociedade americana dos anos 1950. Apesar de ser um texto escrito a mais de 60 anos e refletir sobre a realidade americana, possui uma atualidade impressionante que nos ajuda pensar a complexidade educacional dos nossos dias e a necessidade da formação continuada na perspectiva da educação para o pensar.

Para Arendt (2003), a ilusão emergente "do novo" no campo educacional produziu consequências sérias com o aparecimento das mais variadas teorias educacionais que, sob o rótulo da "educação progressista", destituiu completamente todas as tradições e métodos estabelecidos de ensino e de aprendizagem. Estas novas teorias, aceitas de forma passiva e Revista Digital de Ensino de Filosofia - Santa Maria - vol.2., n.2 - jul./dez. 2016. 
acrítica, acabaram produzindo o desaparecimento do bom senso e com isso a derrocada e a crise de todo sistema educacional contemporâneo.

$\mathrm{Na}$ análise de Arendt (2003), três fatores ocasionaram a derrocada e a crise da educação contemporânea. O primeiro deles diz respeito às mudanças sofridas na concepção de criança. Diante da ideia de "autonomia e emancipação das crianças", próprias das pedagogias modernas, os adultos sentiram-se perdidos e impotentes, sem saber o que fazer e como fazer. Assim, perdidos diante do complexo e angustiante desafio de formar as novas gerações, demitiram-se do intransferível papel de educar os pequenos. No mundo moderno, diz Arendt (2003, p. 230), "existe um mundo da criança e uma sociedade formada entre crianças, e se deve, na medida do possível, permitir que elas governem". Os adultos tornaram-se coadjuvantes, estão aí "apenas para auxiliar esse governo". A autoridade passou a ser do grupo de crianças que decide o que fazer, tornando o adulto "impotente ante a criança individual". A autoridade passa a ser do grupo, não mais do adulto educador. A pretensa emancipação da criança da autoridade dos adultos acabou banindo-as do mundo dos adultos, mas ao invés de se libertarem, passaram a se submeter "a uma autoridade muito mais terrível e verdadeiramente tirânica, que é a tirania da maioria". Como consequência, ressalta Arendt (2003, p.231), "tende a ser o conformismo ou a delinquência juvenil, e frequentemente a mistura de ambos".

Um segundo fator indicado por Arendt (2003, p. 231) "que veio à tona na presente crise tem a ver com o Ensino". Tendo por influência tanto a Psicologia moderna quanto o Pragmatismo, "a Pedagogia transformou-se em uma ciência do ensino em geral a ponto de se emancipar inteiramente da matéria efetiva a ser ensinada". Temos aí a ideia ingênua de que o professor pode "ensinar qualquer coisa" e como consequência "um negligenciamento extremamente grave da formação dos professores em suas próprias matérias". A formação de professores se tornou paupérrima, instrumental, aligeirada. Assim, "não apenas os estudantes são efetivamente abandonados a seus próprios recursos", mas também o professor, uma vez que sua fonte mais legítima de autoridade, que é o ensino sistematizado e qualificado, não se torna mais eficaz.

O terceiro fator que desencadeia a crise educacional deriva da Revista Digital de Ensino de Filosofia - Santa Maria - vol.2., n.2 - jul./dez. 2016. 
expressão conceitual do pragmatismo, "de que só é possível conhecer e compreender aquilo que nós mesmos fizemos" e com isso, substituir "o aprendizado pelo fazer". A ênfase no "fazer" acabou transformando as "instituições de ensino em instituições vocacionais" e com isso, na avaliação de Arendt (2003, p.232), "foram incapazes de fazer com que a criança adquirisse os pré-requisitos normais de um currículo padrão". Essa tentativa de manter a criança à parte, mostrou-se artificial, pois acabou danificando o relacionamento natural entre adultos e crianças, próprios da condição humana. "Aquilo que, por excelência, deveria preparar a criança para o mundo dos adultos, o hábito gradualmente adquirido de trabalhar e de não brincar, é extinto em favor da autonomia do mundo da infância" (ARENDT, 2003, p.233).

Para Arendt (2003, p.234), não é possível contornar a atual crise educacional sem dar-se conta que a criança é um ser em desenvolvimento, a infância é uma etapa temporária e uma preparação para o mundo dos adultos e de que é necessário "transformar os atuais currículos dos professores de modo que eles mesmos tenham de aprender algo antes de se converterem em negligentes para com as crianças". Este último indicativo nos remete a necessidade da formação continuada.

Um dos aspectos positivos da crise educacional foi o de provocar que diversas ciências e instituições passassem a se debruçar sobre a formação dos professores e o cuidado com sua profissionalidade. Diversos estudos e pesquisas, bem como a criação de legislações e o debate público sobre a necessidade de qualificar o trabalho docente, são alguns indicativos que mostram a centralidade da problemática e a urgência em tratar como prioridade este assunto. No âmbito das pesquisas educacionais, a formação docente se tornou um campo fértil para a aplicação de novas teorias educacionais e de novos métodos e técnicas para enfrentar o problema do ensino e da aprendizagem.

De modo geral, os estudos que tratam da formação continuada de professores, abarcam um universo multifacetado e pluridisciplinar inspirado em diferentes paradigmas: histórico-cultural, tecnicista, interacionista, fenomenológico, psicanalítico dentre outros. Não é intenção deste capítulo problematizar, reconstruir ou analisar todos estes paradigmas. Isso extrapolaria Revista Digital de Ensino de Filosofia - Santa Maria - vol.2., n.2 - jul./dez. 2016. 
o escopo deste escrito.

Conforme ressaltam Almeida e Paulo (2010, p.131), "em um passado muito recente e não totalmente superado, o entendimento acerca da formação profissional dos professores era de que uma mera preparação técnica seria suficiente para o desempenho de uma atividade que qualquer um poderia realizar". Esta concepção equivocada de formação profissional reduzia a docência a um mero "jogo de estatutos e papéis mal definidos" e desconsiderava dimensões específicas importantes da identidade docente como o modus operndi do ser professor, a socialização profissional e subjetividade no processo de constituir-se docente dentre outras. Organizar a formação continuada nesta perspectiva poderia se resumir a propor cursos que ensinem o professor a instrumentalizar-se no domínio determinadas técnicas de ensino que ele aplica no cotidiano do seu trabalho. Com isso, uma descaracterização da profissão docente, indicada por Carrolo (1997) como sendo a progressiva incompreensão e ausência de reconhecimento social da função docente, a proliferação de papéis exigidos pelo professor e a deficiente percepção, por parte dos professores, de que sua profissão adentra o labirinto interior do próprio educador, ao questionar-se sobre o sentido do que faz e o modo como os outros entendem e reconhecem sua ação.

Não há dúvidas que tal descaracterização da profissão docente está vinculada com a crise da educação da sociedade moderna diagnosticada por Arendt (2003), na qual o professor se vê, cada vez mais, reduzido a um "serviçal contingente" na estrutura social e cultural, em que a escola, questionada e criticada por todos, assume as mais diversas formas e funções, e na maioria das vezes acaba esquecendo-se de exercer seu papel intransferível e insubstituível. "O modelo de formação preconizado por essa concepção positivista-tecnicista da profissão docente", advertem Almeida e Paulo (2010, p.132), "esvazia o professor de seus saberes, crenças e percepções, experiências e história de vida, negando a força de seu desejo e reduzindo a identidade e as práticas profissionais a um mero arranjo de contingências externas ao sujeito".

Essa concepção acaba excluindo do processo de formação a ideia de que a identidade pessoal, também é constitutiva da dimensão profissional, pois há uma indissociabilidade entre o "eu pessoal" e o "eu profissional". Revista Digital de Ensino de Filosofia - Santa Maria - vol.2., n.2 - jul./dez. 2016. 
Conforme nos diz Nóvoa (2000, p.133), "a identidade não é um dado adquirido, não é uma propriedade, não é um produto. A identidade é um lugar de lutas e de conflitos, é um espaço de construção, de maneiras de ser e de estar na profissão". As reflexões de Nóvoa nos remetem a necessidade de pensarmos os princípios e os desafios da formação continuada numa perspectiva da educação para o pensar.

Na perspectiva da educação para o pensar, o professor não deve apresentar-se como a "fonte de informação" ou a "autoridade do conhecimento", pois com isso estaria "minando" a noção de "comunidade de investigação". Para Lipman (1990, p. 117), numa sala de aula compreendida como uma comunidade de investigação, professor e alunos são "coinvestigadores" no processo de construção do conhecimento. Compete ao professor nesta perspectiva estabelecer as condições favoráveis e necessárias para que turma toda se envolva numa "investigação discursiva, mais e mais produtiva, mais e mais autocorretiva", para que a aprendizagem aconteça. Isso não significa minimizar o papel do professor no processo de discussão. Ao contrário, como membro da comunidade de investigação e como adulto na relação pedagógica, o professor também tem o direito de propor temas de investigação sem impor sua vontade os assuntos de sua preferência. Para isso, o professor precisa estar vigilante consigo mesmo e com o grupo a fim de evitar qualquer tipo de "doutrinação". Nas palavras do próprio Lipman (1990, p.207), "o professor deve ser auto-retraído filosoficamente (sempre atento ao risco de fazer doutrinação inconscientemente) e, contudo, pedagogicamente forte (sempre promovendo o debate entre as crianças e as encorajam a seguir a investigação na direção que ele aponta)".

Em seu texto "Algumas sugestões para implementar filosofia com crianças em escolas", Walter Kohan (1998, p.105) ressalta que "o lugar do docente na discussão é tremendamente significativo e delicado", pois enquanto professores "não temos que demonstrar nem transmitir nenhum saber em particular"; ao contrário, é recomendável que tenhamos o espírito socrático, ou seja, "reconhecer que não sabemos as respostas às questões e problemas que as crianças levantam" e desta forma juntos, professor e alunos, "empreender uma busca compartilhada de questionamento e investigação", pois os melhores professores de filosofia, "não são aqueles que 'mais sabem', Revista Digital de Ensino de Filosofia - Santa Maria - vol.2., n.2 - jul./dez. 2016. 
mas aqueles que desejam saber". Tal atitude filosófica e pedagógica não se traduz em cinismo ou "valorização da ignorância", mas como "reconhecimento do valor da inquietação e da insatisfação, próprios da filosofia diante das respostas presumidamente definitivas a questões relevantes da experiência humana".

Não resta dúvida que um professor somente consegue colocar-se nesta condição de mediador do processo investigativo com as crianças se passar por um processo formativo que oportunize compreender e exercitar este tipo de postura. Dificilmente um professor consegue se colocar como alguém que mantêm uma "reflexividade atenta, solícita e proporcionadora da dúvida, da inquietude, da curiosidade, da inventiva, da descoberta, do ensaio, da busca e da exploração (KOHAN, 1998, p.106), se não tiver em seu fazer pedagógico a atitude de abertura que se constitui com sólidos e consistentes processos de formação.

\section{Conclusão}

Após termos aprofundado o conceito do "pensar de ordem superior", o eminente contributo do diálogo filosófico como cerne para o seu desenvolvimento e a relação intrínseca entre a formação continuada de professores e a educação para o pensar, lançaremos algumas pistas em tom conclusivo, destacando novamente a importância e os contributos do Programa de Filosofia com Crianças para o contexto educacional atual.

Um primeiro aspecto diz respeito ao aperfeiçoamento da criticidade, visto que, muito se cobra da escola a formação de cidadãos críticos, entretanto, a escola tem dificuldades metodológicas, estruturais e ideológicas que não permitem avançar nesta dimensão. Talvez pior que isso, seja o enorme desconhecimento do que signifique uma educação crítica. De acordo com o que expomos acima, acreditamos que o programa de filosofia com crianças vem para somar ao contemplar em sua essência a relação entre o pensamento criativo e crítico, imprescindíveis para o pensar com mais habilidade.

Um segundo contributo é o fortalecimento de propostas 
interdisciplinares nas escolas. A comunidade de investigação ultrapassa os limites da filosofia e dialoga por meio da lógica, da ética, da metafísica, com uma gama expressiva de problemas, dilemas e interrogações. A inserção da filosofia ao currículo ou a sua permanência é compreendida na ótica lipmaniana, não como algo que irá espremer em espaços menores o tempo dos demais componentes curriculares, mas antes entendida como uma matéria miscível que permeia as outras, enriquecendo-as.

Diante do desafio de transformar as relações no âmbito escolar em relações dialógicas e democráticas, encontramos na comunidade de investigação uma terceira contribuição que é sem dúvida o fortalecimento de processos democráticos nas escolas, tanto na investigação filosófica, quanto na busca de padrões éticos e responsáveis em conjunto com as crianças e jovens. Lipman afirma que a comunidade de investigação precede a demanda pelo pensamento crítico nas escolas, e "é comprovadamente o melhor exemplo do tipo de reforma educacional que pode ocorrer" (2008, p. 353).

Por fim, dado o papel fundamental da preparação dos professores para uma proposta de educação para o pensar, torna-se importante ressaltar duas coisas: primeiro, que a academia e os cursos de formação de professores precisam preparar com maior desembaraço os atuais e futuros professores. Segundo, que é preciso ir além desses espaços já consolidados e criar possibilidades, cursos e formações específicas comprometidas com o programa de filosofia com crianças. Se esperamos que os professores coordenem diálogos filosóficos, devemos garantir-lhes a participação dos mesmos, para modelar o modo investigativo dialógico-filosófico. Se quisermos que os educadores estimulem um comportamento questionador nos alunos, devem ser formados por professores que modelem esse tipo de atitude nas aulas. Nas palavras de Lipman, "se se espera que os professores ensinem as crianças a raciocinar, devemos proporcionar-lhes prática no raciocínio que eles mesmos esperam de seus alunos" (2014, p. 79).

A educação para o pensar, na medida em que for assumida com autenticidade, poderá se tornar uma proposta de escola e ser um efetivo e inovador paradigma educacional. 


\section{Referências}

ALMEIDA, Sandra Francesca Conte de; PAULO, Thais Sarmanho. Formação de professores: desenvolvimento pessoal e aperfeiçoamento profissional: apontamentos para uma reflexão necessária. In: FREITAS, Lêda Gonçalves de;

MARIZ, Ricardo Spindola; CUNHA FILHO, José Leão da (orgs.). Educação Superior: Princípios, finalidades e formação continuada de professores. Brasília: Líber Livro, 2010, pp.123-148.

ARENDT, Hannah. Entre o passado e o futuro. 5 ed. São Paulo: Perspectiva, 2003.

CARROLO, C. Formação e identidade profissional dos professores. In: ESTRELA, M. T. (ORG.). Viver e construir a profissão docente. Porto: Porto, 1997, p.21-50.

ELIAS, Gisele, P. Matthew Lipman e a filosofia pra crianças. 2005. Dissertação (Mestrado em Educação) - Universidade Católica de Goiás, Goiânia, 2005.

FÁVERO, Alcemira. M. As estratégias de diálogo na prática filosófica: elementos metodológicos necessários à educação para o pensar. In: FÁVERO, Altair. A; CASAGRANDA, Edison. Diálogo e aprendizagem: orientações teóricometodológicas do ensino de filosofia com crianças. Passo Fundo: Clio, 2001. p. 65-88

FÁVERO, Alcemira. M. O diálogo como encontro hermenêutico. In: FÁVERO, A. M. et al. Diálogo e investigação: perspectivas de uma educação para o pensar. Passo Fundo: Méritos Editora, 2007. p. 43-62.

KOHAN, Walter. Sugestões para implementar filosofia com crianças em escolas. In: KOHAN, W.; WAKSMAN, V. (orgs.). Filosofia para crianças na prática escolar. 2 ed. Petrópolis: Vozes, 1998, p.85-112.

LIPMAN, Matthew. A filosofia vai à escola. São Paulo: Summus, 1990.

LIPMAN, Matthew. O pensar na educação. 4. ed. Petrópolis: Vozes, 2008.

LIPMAN, Matthew; OSCANYAN, Frederick; SHARP, Ann Margaret. Filosofia na sala de aula. São Paulo: Nova Alexandria, 2001.

TONIETO, C. A prática dialógica na comunidade de investigação: possibilidades de uma educação para o pensar. In: FÁVERO, A. M. et al. Diálogo e investigação: perspectivas de uma educação para o pensar. Passo Fundo: Méritos Editora, 2007. p. 20-41 


\title{
Experiências metodológicas de ensino no Pibid Filosofia da Universidade Federal do Ceará
}

\author{
Evanildo Costeski20 \\ José Carlos Silva de Almeida ${ }^{21}$
}

\begin{abstract}
Resumo: O presente relato apresenta duas experiências metodológicas de ensino de filosofia desenvolvidas no âmbito do subprojeto PIBID Filosofia da Universidade Federal do Ceará, nas quais os conteúdos filosóficos ministrados valorizam a vivência do discente como ponto de partida para a reflexão e ao qual se busca, ao fim do processo, transformar a sua realidade cotidiana.
\end{abstract}

Palavras-chave: ensino; filosofia; metodologias; cotidiano.

\section{Experiencias metodológicas de enseñanza en PIBID Filosofía de la Universidad Federal de Ceará}

Resumen: El presente informe presenta dos experiencias metodológicas de enseñanza de filosofía desarrolladas en el ámbito del sub-proyecto Programa Institucional de Beca de Iniciación a la Docencia - Filosofía (PIBID) de la Universidad Federal del Ceará, en las cuales los contenidos filosóficos trabajados valoran la experiencia del alumno como punto de partida para la reflexión y en los cuales se busca, al final del proceso, cambiar su realidad cotidiana.

Palabras clave: enseñanza; filosofía; metodologías; cotidiano.

\section{Introdução}

O projeto Pibid Filosofia da Universidade Federal do Ceará teve início em 2008 com o primeiro edital nacional do Pibid. Na oportunidade, as licenciaturas priorizadas pela Capes foram Matemática, Química, Biologia e

20 Mestre e Doutor em Filosofia pela Pontifícia Universidade Gregoriana (Roma), com estágio de pós-doutorado no Centro de História de Cultura da Universidade Nova de Lisboa. Atuou como professor de Filosofia no Ensino fundamental e Médio de 1993 a 1995. Desde 2005 é Professor do Curso de Filosofia da Universidade Federal do Ceará. É coordenador de área do subprojeto Filosofia PIBID UFC. E-mail: evanildoc@uol.com.br 21 Bacharel, Licenciado e Mestre em Filosofia pela Pontifícia Universidade Católica do Rio de Janeiro (PUC/RJ). Doutor em Filosofia pela Pontifícia Universidade Antonianum (PUA) em Roma. Atuou como Professor do Ensino Fundamental e Médio nas áreas de Filosofia e Ensino Religioso, no período de 1989 a 1997, no Rio de Janeiro. Desde 2007 é Professor do Curso de Filosofia da Universidade Federal do Ceará (UFC). É coordenador de área do subprojeto Filosofia Pibid UFC. E-mail: jcdafilosofia@hotmail.com

Revista Digital de Ensino de Filosofia - Santa Maria - vol.2., n.2 - jul./dez. 2016. 
Física, consideradas as áreas mais carentes de professores no nível médio de ensino. Não obstante a priorização de certas licenciaturas, o curso de Filosofia da UFC conseguiu participar do projeto institucional pelo fato de apresentar uma proposta voltada à interdisciplinaridade. Essa característica está sendo mantida em todos os trabalhos executados até o momento presente, em cumprimento do que reza a Portaria Capes n 96, de 18 de julho de 2013 em vários trechos de sua redação:

Inserir os licenciandos no cotidiano de escolas da rede pública de educação, proporcionando-lhes oportunidades de criação e participação em experiências metodológicas, tecnológicas e práticas docentes de caráter inovador e interdisciplinar que busquem a superação de problemas identificados no processo de ensinoaprendizagem [grifo nosso]. ${ }^{22}$

Desenvolvimento de ações que valorizem o trabalho coletivo, interdisciplinar e com intencionalidade pedagógica clara para 0 processo de ensino-aprendizagem [grifo nosso]. ${ }^{23}$

Com efeito, se é verdade que o ensino constitui um desafio constante para todas as áreas, é um fato que a aprendizagem dos conteúdos das ciências consideradas mais "duras" - Matemática, Física e áreas afins -, sofre com o crescente desinteresse dos alunos das escolas públicas, principalmente daquelas existentes nas periferias das grandes cidades, como é o caso de Fortaleza. O nosso projeto visava justamente buscar reverter essa situação, estando dessa forma em perfeita consonância com que afirma a Portaria $n^{\circ} 96$ da Capes sobre o Pibid:

O Pibid é um programa da Coordenação de
Aperfeiçoamento de Pessoal de Nível Superior
(Capes) que tem por finalidade fomentar a
iniciação à docência, contribuindo para o
aperfeiçoamento da formação de docentes em
nível superior e para a melhoria da qualidade da
educação básica pública brasileira [grifo nosso]. ${ }^{24}$

O nosso ponto de partida para a mudança do cenário fora a própria situação

22 Capítulo I - Disposições Gerais - Seção II - Dos Objetivos - Inciso IV do Artigo 4º p. 2.

${ }^{23}$ Capítulo II - Do Projeto - Seção I - Das Características do Projeto e Subprojetos - Inciso Il do Artigo 6०, p. 3.

${ }^{24}$ Capítulo I - Disposições Gerais - Seção I - Da Definição - Artigo 2º , p. 2.

Revista Digital de Ensino de Filosofia - Santa Maria - vol.2., n.2 - jul./dez. 2016. 
do aluno de ensino médio. Pelo fato de sofrer constantemente pressões subjetivas e objetivas, tanto psico-afetivas quanto sócio-econômicas, o aluno das escolas públicas do ensino médio encontra-se normalmente em uma situação de vulnerabilidade, distante de um aprendizado satisfatório. Somamse a isso as preocupações técnicas do mundo do trabalho, que passam igualmente a fazer parte da vida do jovem estudante. Diante desse quadro de precariedade, o ensino de filosofia, se quiser apresentar algum resultado concreto, deve propor algumas possíveis soluções. A princípio, a reflexão filosófica possibilita aos alunos compreenderem melhor a sua realidade imediata, ajudando-os a conquistar sua autonomia afetiva e social, necessárias para um melhor aprendizado em ciências, sejam elas as humanas, as sociais, as naturais ou as exatas. No que diz respeito especificamente às ciências naturais e exatas, cabe à filosofia esclarecer igualmente as fundamentações epistemológicas e éticas das atividades científicas, pois se é verdade que a racionalização científica é autônoma, é verdade também que não pode prescindir do discurso ético e moral. A atividade científica deve ter um sentido para os jovens estudantes. Ora, a filosofia pode perfeitamente esclarecer esse sentido. Essa era a preocupação principal do Pibid Filosofia da UFC no momento de sua implantação, a saber, propiciar aos estudantes do ensino médio e aos licenciandos do curso de Filosofia os meios adequados para poderem articular ciência e vida, teoria e prática, aproximando, assim, os conteúdos filosóficos à vida dos jovens e das ciências em geral.

Paralelo a essa atividade interdisciplinar, o Pibid Filosofia aspirou desde o início a garantir uma maior autonomia para o ensino de filosofia nas escolas, pelo fato de a filosofia finalmente ter se tornado uma disciplina obrigatória no ensino médio, com o Parecer do Conselho Nacional de Educação n 38/2006 homologado em 14/08/2006 - e o Projeto de Lei 11.684, de 02 de junho de 2008, que altera o parágrafo 36 da Lei de Diretrizes e Base da Educação Nacional. Durante muitos anos, o ensino de filosofia ficou ausente da maioria das escolas brasileiras. Isso fez com que os cursos universitários de graduação em filosofia se distanciassem do ensino médio e passassem a se preocupar mais com a pesquisa filosófica do que com o seu ensino, acentuando a formação de bacharéis. Essa situação felizmente está mudando. Mas muito precisa ainda ser feito, principalmente em relação às metodologias de ensino Revista Digital de Ensino de Filosofia - Santa Maria - vol.2., n.2 - jul./dez. 2016. 
de filosofia. 25 O Pibid Filosofia da UFC assumiu, em seu projeto inicial e mantém até hoje, essa incumbência. $\bigcirc$ ensino de filosofia deve ser histórico, temático ou histórico-temático? O professor deve "ensinar filosofia" ou "ensinar a filosofar"? São questões que não podem ser negligenciadas. O que se constatou é que o ensino de filosofia não pode se restringir apenas ao aprendizado histórico dos conteúdos filosóficos. Embora fundamentais, os conteúdos filosóficos deverão ser contextualizados para que os jovens possam pensar, em sala de aula e em grupos de estudos, a sua situação vivida.

Nota-se, com isso, que as formações humanísticas e científicas não podem ser separadas. A filosofia oferece todas as condições para se pensar uma educação interdisciplinar, onde valores morais e éticos possam coexistir com pesquisas científicas, sem prejuízos para $\circ$ meio-ambiente e 0 desenvolvimento da civilização humana. A esse respeito a Portaria da Capes sobre $O$ Pibid afirma que $O$ projeto deve contemplar "questões socioambientais, éticas e a diversidade como princípio de equidade social, que devem perpassar transversalmente todos os subprojetos". 26 Deve-se apenas ressaltar que essa função não é específica da filosofia. Todas as ciências devem visar à formação integral dos jovens.

\section{A Metodologia do Professor Silvio Gallo}

Para se alcançar esse objetivo, o projeto Pibid Filosofia buscou inspiração, em um primeiro momento, na metodologia proposta pelo Professor Silvio Gallo, da Unicamp. A filosofia deve trabalhar com dois conteúdos: um sistemático e coerente, oriundo dos textos e dos filósofos que constituem a História da Filosofia; e outro mais assistemático e incoerente, originário da própria vivência dos alunos. Mas qual seria a metodologia mais adequada?

Para Sílvio Gallo, "ensinar filosofia é ensinar o ato, o processo do

25 A Portaria $n^{\circ} 96$ da Capes sobre o Pibid faz alusão a essa questão quando afirma que se deve "inserir os licenciandos no cotidiano de escolas da rede pública de educação, proporcionando-lhes oportunidades de criação e participação em experiências metodológicas, tecnológicas e práticas docentes de caráter inovador e interdisciplinar que busquem a superação de problemas identificados no processo de ensino-aprendizagem" [grifo nosso]. Cf. nota 1.

${ }^{26}$ Capítulo II - Do Projeto - Seção I - Das Características do Projeto e Subprojetos - Inciso $\checkmark$ do Artigo $7^{\circ}$, p. 4.

Revista Digital de Ensino de Filosofia - Santa Maria - vol.2., n.2 - jul./dez. 2016. 
filosofar" (2007, p. 16). Para tanto, ele desenvolve quatro momentos: Sensibilização, Problematização, Investigação e Criação de Conceitos (GALLO, 2007, p. 25-31). A nossa proposta também envolve quatro etapas, com algumas adaptações. A primeira é chamada de Problematização inicial. Nesta fase, o pensamento filosófico é apresentado ao estudante do ensino médio não de forma dogmática, mas a partir de um estado de crise, ou seja, de uma tomada de consciência dos problemas da vida humana, da sociedade e do mundo em geral. Assim como a etapa da Sensibilização de Sílvio Gallo, o objetivo deste momento é fazer com os estudantes vivam e "sintam na pele" um problema filosófico a partir de um elemento não-filosófico (GALLO, 2007, p. 26). Para essa problematização inicial, são utilizados recursos diversos, tais como: filmes, documentários, letras de músicas, programas de televisão, trechos de obras literárias, etc., em suma, algo que desperte a atenção dos alunos.

Após o levantamento de temas e problemas gerais vividos pelos estudantes, os alunos bolsistas do Pibid Filosofia, junto com o professor supervisor, são convidados a fazer uma primeira classificação dos mesmos. Evidentemente, não se trata ainda de uma classificação filosófica, mas apenas metodológica. Passa-se então para a segunda etapa, denominada Investigação dos problemas. Esta pode ser feita de duas maneiras: uma mais temática e outra mais histórica. A temática se concentra sobre os problemas levantados pelos alunos e classificados preliminarmente pelo professor supervisor e pelos bolsistas. Com base nessa classificação, os bolsistas selecionam textos filosóficos apropriados à problemática levantada. Por exemplo: para problemas éticos e morais, podem ser selecionados textos de filósofos clássicos (Platão, Aristóteles e Epicuro) e de modernos e contemporâneos (Descartes, Kant e Levinas), por exemplo; para questões existenciais, destacam-se as contribuições de Kierkegaard, Camus e Sartre; enquanto para problemas sociais e econômicos, textos de Karl Marx e assim por diante. Após a leitura de trechos selecionados das obras de autores clássicos e contemporâneos, os alunos bolsistas tratam de discutir com os estudantes, buscando a contextualização dos textos filosóficos. Nesse momento, busca-se esclarecer dúvidas sobre o pensamento do filósofo, da sua vida e da sua relação com a história humana em geral. Nesse processo Revista Digital de Ensino de Filosofia - Santa Maria - vol.2., n.2 - jul./dez. 2016. 
prioritariamente temático, a história da filosofia não será ainda o centro da investigação, mas "um recurso necessário para pensar o nosso próprio tempo, nossos próprios problemas" (GALLO, 2007, p. 26). Com o tempo, depois de várias leituras de textos filosóficos do período clássico, moderno e contemporâneo, o aluno poderá alcançar uma visão mais ampla e geral da história da filosofia. Bem entendido: o objetivo primeiro da investigação temática será a reflexão sobre as questões atuais, não o conhecimento aprofundado da história da filosofia.

Já na investigação histórica, por sua vez, os problemas atuais continuam a ser o foco principal, mas, ao contrário do processo temático, a reflexão sobre eles será indireta, a partir da própria interpretação da história da filosofia. Para isso, o estudo da história da filosofia deverá ser contextualizado, de acordo com as questões levantadas pelos alunos e classificadas previamente. Por exemplo: depois da apresentação de alguns mitos, os bolsistas poderão trabalhar com alguns diálogos platônicos, como A República, a Apologia de Sócrates e O Banquete. Através do Mito da Caverna, narrativa que abre o sétimo livro de A República de Platão, poderse-á falar da alienação midiática contemporânea; já a Apologia destaca, entre outros problemas, o da violência, o da aplicação da lei e da justiça, e O Banquete das diversas formas de amor, que constituem, certamente, um discurso sempre atraente aos jovens.

No período moderno, a leitura das duas primeiras meditações de Descartes pode levar o jovem a questionar o seu conhecimento sobre a realidade. Será que estou sonhando? O que estou vendo passar diante dos meus olhos será um homem ou um robô? São questões que podem ir ao encontro de várias indagações destacadas pelos jovens na primeira etapa. Os famosos quatro ídolos de Bacon, que bloqueiam a mente humana: ĺdolos da Tribo, Ídolos da Caverna, Ídolos do Foro e ídolos do Teatro, ajudam outrossim a mostrar para o aluno que a nossa mente pode estar impregnada de conceitos falsos e ideológicos; enquanto a leitura de partes do Manifesto Comunista de Karl Marx revela ao jovem as situações injustas presentes no trabalho, na economia e na sociedade atual.

Enfim, na investigação histórica, cabem aos bolsistas selecionarem textos e interpretá-los de forma contextualizada, respeitando o próprio Revista Digital de Ensino de Filosofia - Santa Maria - vol.2., n.2 - jul./dez. 2016. 
desenvolvimento do pensamento filosófico. O resultado é semelhante ao da investigação temática, já que ambos os processos têm como foco principal os problemas classificados na primeira fase. A diferença é apenas metodológica. $\mathrm{Na}$ investigação temática, os textos são selecionados a partir dos temas previamente classificados, enquanto na histórica os textos são lidos e estudados de forma sistemática, respeitando o percurso histórico; apenas no final são contextualizados de acordo com os temas selecionados.

Para o professor Sílvio Gallo, a Criação de Conceitos é a última etapa do processo de ensino. Sugerimos que esta seja uma terceira etapa, seguida de uma quarta, chamada de Socialização de Conceitos. Isso porque a criação constitui um processo puramente individual que precisa, certamente, ser socializado com os demais alunos em sala de aula. Para definir o ensino de filosofia como criação de conceitos, Sílvio Gallo cita os filósofos franceses Deleuze e Guattari:

O filósofo é o amigo do conceito, ele é o conceito em potência. Quer dizer que a filosofia não é uma simples arte de formar, de inventar ou de fabricar conceitos, pois os conceitos não são necessariamente formas, achados ou produtos. A filosofia, mais rigorosamente, é a disciplina que consiste em criar conceitos (...) Criar conceitos sempre novos é o objeto da filosofia. É porque o conceito precisa ser criado que ele remete ao filósofo como aquele que o tem em potência, ou que tem sua potência e sua competência (...) Os conceitos não nos esperam inteiramente feitos, como corpos celestes. Não há céu para os conceitos. Eles devem ser inventados, fabricados ou antes criados, e não seriam nada sem a assinatura daqueles que os criam (...) Que valeria um filósofo do qual se pudesse dizer: ele não criou um conceito, ele não criou seus conceitos? (DELEUZE; GUATTARI, 2007, p. 13-14; GALLO, 2007, p. 23).

Bem entendido: não se trata aqui de um "conceito científico", abstrato, mas de "uma forma racional de equacionar um problema ou problemas, exprimindo uma visão coerente do vivido; isto é, o conceito é uma forma de lançar inteligibilidade sobre o mundo" (GALLO, 2007, p. 23). O estudante será motivado a criar conceitos em sala de aula, com base na leitura de textos 
filosóficos e discussões com o professor e demais alunos. Os conceitos não precisam ser definitivos nem precisam explicar todos os problemas. Esses podem ser fundamentados não apenas na filosofia, mas também nas ciências em geral. $O$ jovem estudante do ensino médio poderá criar inicialmente apenas um conceito pessoal, para explicar sua própria experiência e, assim, orientar filosoficamente a sua vida. Isso não obscurece o fato de ele ter feito, de forma autônoma, uma experiência de pensamento. Nesse momento, é importante que 0 professor deixe 0 estudante a vontade, para que 0 pensamento possa fluir livremente, orientando-o apenas quando necessário.

Por fim, apresentamos a última etapa, chamada por nós de Socialização dos conceitos: após a criação individual de conceitos filosóficos iniciais, os estudantes do ensino médio são encorajados a partilhá-los com os outros colegas da sala. Nesse momento, os conceitos poderão ser criticados, possibilitando, assim, um amadurecimento do aprendizado filosófico. O importante é que o aluno aprenda a discutir e a compartilhar sua experiência reflexiva. A socialização de saberes é fundamental para o ensino médio. Da mesma forma que outros conhecimentos, os conceitos filosóficos precisam ser compartilhados. A socialização pode ser feita tanto em sala de aula, como em semanas específicas, destinadas a trabalhos científicos e culturais na Escola. Essa experiência é importante porque faz com que a filosofia se integre mais no currículo escolar e nas atividades interdisciplinares, necessárias para o crescimento intelectual do aluno.

Como já foi dito, os conceitos não são meros instrumentos científicos, mas verdadeiras armas que podem servir para transformar a vida do aluno e o meio em que vive. Eis como conclui Sílvio Gallo (2007, p. 31):

\footnotetext{
Os conceitos são ferramentas, e podem ser armas, dependendo do uso que deles fazemos. É claro que as armas não são boas ou más em si mesmas; os conceitos podem ser armas de transformação ou armas de conservação, dependendo das intenções de quem os usa. A aula de filosofia como oficina de conceitos está longe, portanto, de ser um empreendimento ingênuo ou alienado. Pode ser arma de luta; o conceito pode ser ferramenta de engajamento.
} 
Mas uma arma ou ferramenta de transformação pode ser institucionalizada oficialmente? Como conciliar a criação de conceitos filosóficos com o currículo escolar? Como a filosofia pode ser revolucionária dentro da instituição escolar brasileira? É suficiente afirmar que a filosofia é necessária para a formação da cidadania e da democracia para torná-la revolucionária? São questões que precisam ser devidamente esclarecidas, para que a filosofia possa cumprir o seu papel na educação dos jovens. Para isso, é necessário que a filosofia extrapole os limites da sala de aula e passe a atuar na escola e na comunidade como um todo.

Com efeito, a socialização dos conceitos não pode ser feita apenas em sala de aula, mas também na comunidade em que se encontra a escola. A escola não é apenas um espaço para o ensino formal. Ela representa um ponto de apoio acadêmico, cultural e esportivo para muitas comunidades. As salas de aula continuam a ser o foco principal, mas existem muitas outras atividades na escola e na comunidade que exigem atenção dos alunos, como as preparações específicas para o Enem, para as Olimpíadas de Conhecimento etc. A filosofia não pode ficar alheia a essas atividades. Além dessas atividades prioritariamente acadêmicas, pode-se pensar em atividades interdisciplinares e debates culturais sobre cinema e filosofia, literatura e filosofia e assim por diante, não apenas para os alunos da escola, mas para os pais dos alunos e toda a comunidade próxima à escola. ${ }^{27}$

Essa foi, em linhas gerais, a proposta inicial do Pibid Filosofia da UFC. Nem tudo foi aplicado como se previa inicialmente. As atividades escolares têm uma dinâmica própria que extrapolam muitas vezes as intenções iniciais. Mas o espírito geral do projeto foi cumprido, a saber, inserir, de forma interdisciplinar, as questões filosóficas na vida dos estudantes, a partir de problemas levantados pelos mesmos. Isso se deu na prática mediante dois grandes projetos, realizados no ano de 2010 em duas escolas de Fortaleza, com resultados bastante significativos: "Pensando naquilo", sobre a questão

27 A Portaria $n^{\circ} 96$ da Capes sobre o Pibid postula que o projeto institucional deve abranger diversas características e dimensões da iniciação à docência, sendo uma delas a de "elaboração de ações no espaço escolar a partir do diálogo e da articulação dos membros do programa, e destes com a comunidade". Cf. Inciso IX do Artigo $6^{\circ}$ - Capítulo II - Do Projeto - Seção I - Das Características do Projeto e Subprojetos, p. 3.

Revista Digital de Ensino de Filosofia - Santa Maria - vol.2., n.2 - jul./dez. 2016. 
da sexualidade na adolescência, realizado no Liceu de Messejana e o projeto sobre "Alimentação", no Liceu do Conjunto Ceará.

\section{A Teoria do Cotidiano de Agnes Heller}

A partir de 2012, houve uma significativa ampliação nas atividades do Pibid Filosofia da UFC. O trabalho que até então se desenvolvera em duas escolas apenas, a saber, o Liceu de Messejana e o Liceu do Conjunto Ceará, com um contingente de cinco alunos e um professor supervisor por escola, é estendido para uma terceira instituição de ensino médio, a saber, o Colégio Estadual Justiniano de Serpa, localizado no centro de Fortaleza, conhecida como uma das escolas públicas cearense de regime integral. ${ }^{28}$ Vale salientar aqui que a ideia de integralidade levada adiante no Colégio Justiniano de Serpa pauta-se fundamentalmente numa duplicação do tempo disponibilizado para as diversas áreas do conhecimento quando se compara com as demais escolas de ensino médio do Estado do Ceará. Soma-se uma hora/aula a já tão exígua hora/aula semanal ofertada ao ensino de filosofia. Com uma grade de horário semanal centrada em sala de aula, pouco espaço fica destinado para as ações dos bolsistas do subprojeto Filosofia do Pibid nos horários entre turnos, enquanto a figura do contra turno é inexistente. Por sua vez as ações interdisciplinares tornam-se restritas aos momentos ou semanas culturais do colégio.

Mas, face a tal cenário, em que o trabalho fica mais situado na sala de aula, deve-se destacar o emprego de um outro referencial teórico no que diz respeito à metodologia de ensino de filosofia. A professora supervisora adota a Teoria do Cotidiano de Agnes Heller, autora de obras como O Cotidiano e a História (1972), Sociologia de la vita cotidiana (1991) e Para mudar a vida (1982), e as suas possibilidades de emprego na área educacional, observando que a dimensão de cotidiano é por diversas vezes uma dimensão menosprezada pela própria filosofia e pelas ciências sociais.

28 Nesse sentido cumprimos a recomendação da Capes na Portaria $n^{\circ} 96$ que trata sobre o Pibid quando afirma que as ações do projeto devem ser desenvolvidas também em escolas de regime de tempo integral. Cf. Inciso II do Artigo $8^{\circ}$ - Capítulo II Do Projeto - Seção I - Das Características do Projeto e Subprojetos, p. 4. 
A prática metodológica dinamizada com o emprego da Teoria do Cotidiano de Agnes Heller abre-se para a percepção de que a reflexão filosófica, a partir do não cotidiano, é necessária para um aprofundamento histórico-crítico mediante uma diversidade de perspectivas, quer seja dentro da esfera do cotidiano, quer seja no âmbito do não cotidiano. Caso contrário, o cotidiano gera um dinamismo limitado, um círculo vicioso, que impossibilita o seu aprofundamento e, conseqüentemente, sua superação.

O cotidiano é uma realidade inegável e vivenciada por todos, mas nem todos percebem o não cotidiano. Perceber os dois numa perspectiva filosófica tem colaborado para o exercício da aprendizagem, mas exige, por parte do professor, a aproximação ao dia-a-dia do aluno e o conhecimento das diversas manifestações de linguagem e de expressões simbólicas que formam o seu cotidiano: a moda, a musicalidade, seus gestos, suas relações com os ídolos, etc. Nesta perspectiva, os elementos de analogia utilizados durante o processo de ensino-aprendizagem são pertencentes, direta e/ou indiretamente, à realidade dos alunos. Há uma visão ingênua que considera que a Teoria do Cotidiano não acolhe a necessidade de aprofundamento teórico, o que não corresponde, pois com o uso da cotidianidade como elemento colaborador da aprendizagem, ocorre a associação do conceito filosófico ao dinamismo da sociedade.

Com isso, os alunos devem ser estimulados ao exercício da superação dos limites impostos pelos pensamentos preconcebidos (preconceitos). A construção do conhecimento se dá a partir da iniciativa dos próprios alunos, por isso o professor adota uma postura de mediador entre os alunos e os conhecimentos filosóficos. Em busca de uma renovação na prática pedagógica é possivel observar professores de filosofia que focam suas aulas em temas cotidianos e montam dinâmicas de grupo, sem que estabeleçam relações entre os temas em debate e os conceitos filosóficos. Em assim ocorrendo, distanciam-se da vivência da Teoria do Cotidiano, pois o exercício reflexivo será limitado, marcado pelo uso freqüente e sem propósitos filosóficos de dinâmicas abusivas. A própria escolha dos temas que servirão de base para os debates ocupa, por si só, um lugar teórico metodológico na Teoria do Cotidiano. A sua escolha não pode ficar, tão somente, a cargo dos alunos. Ocorrendo isso, os professores poderão ficar emersos pela imposição de temas Revista Digital de Ensino de Filosofia - Santa Maria - vol.2., n.2 - jul./dez. 2016. 
predominantes, disseminados pelos interesses midiáticos, terminando por fortalecer o processo de alienação. As escolhas das temáticas têm que apresentar vínculo com o pensar filosófico. Os temas devem contribuir para desvelar realidades, tais quais, elucidar a grande pergunta antropológica da Filosofia: "O que é o Homem?", para ajudar a desvelar o funcionamento da sociedade baseada na produção de mercadorias e tentar compreender o sentido da vida.

O processo educacional requer, portanto, o cuidado em não se cair no mecanicismo; para isso, Agnes Heller nos remete à necessidade de superarmos a formação para a mera individualidade em favor de uma educação que conduza $\circ$ aluno a perceber sua condição de singularidade e de particularidade. Esse é o pressuposto para que o aluno se eleve de sua condição individual para uma visão de pertencimento à coletividade, à comunidade, ao gênero humano.

\section{Conclusão}

Em 2014, com o novo edital da Capes para o Pibid, o subprojeto Filosofia da Universidade Federal do Ceará passou por uma nova ampliação. Atualmente o nosso subprojeto atua em 04 escolas públicas do ensino médio em Fortaleza, envolvendo 02 coordenadores de área, 04 professores supervisores e 28 bolsistas de iniciação à docência. Dos egressos, vários já são docentes em escolas públicas e privadas do Estado do Ceará e participam do Programa de Pós-graduação em Filosofia da UFC. Vale acrescentar ainda, por último, que 02 ex-alunos do Pibid Filosofia são atualmente professores supervisores.

Quando novamente se discute se a filosofia deve permanecer como disciplina ou apenas como conteúdo transversal no Ensino Médio, salientamos que nossa experiência com o PIBID Filosofia prova que o ensino "disciplinar" é realmente essencial. Parece de fato contraditório enquadrar o conteúdo filosófico em uma "disciplina". Não seria mais coerente com a liberdade filosófica a transversalidade, em vez de um conteúdo disciplinar, sujeito ao controle de presença, às avaliações e reprovações próprias das disciplinas? É certo que o conteúdo filosófico não se limita ao ensino curricular, entretanto, Revista Digital de Ensino de Filosofia - Santa Maria - vol.2., n.2 - jul./dez. 2016. 
não podemos esquecer daquilo que é óbvio: não existe de fato interdisciplinaridade sem disciplinas curriculares. Sem a obrigatoriedade da filosofia no Ensino Médio, o conteúdo filosófico seria aos poucos relativizado e terminaria fatalmente se perdendo em meios a tantas outras preocupações tidas como mais técnicas e urgentes.

\section{Referências}

CAPES. Portaria $n^{\circ}$ 96, de 18 de julho de 2013. Aperfeiçoa e atualiza as normas do Programa Institucional de Bolsa de Iniciação à Docência. Disponível em

<https://www.capes.gov.br/images/stories/download/legislacao/Portaria_096_ 18jul13_AprovaRegulamentoPIBID.pdf>. Acesso em: 31 mar. 2015.

COSTESKI, Evanildo. Considerações sobre o Ensino de Filosofia no Nível Médio. In: SOUZA, Vinícios R.; FICK, Vera M. S. (Org.). Epistemologia e Tecnologias para o Ensino das Ciëncias Humanas e Sociais. Fortaleza: Tiprogresso, 2009, v. 03, p. 12-26.

DELEUZE, Gilles; GUATTARI, Félix. O que é a Filosofia? Rio de Janeiro: Editora 34, 2007. SILVEIRA,

GALLO, Sílvio. A filosofia e seu ensino: conceito e transversalidade. In:

René J. T.; GOTO, Roberto. Filosofia no Ensino Médio: Temas problemas e propostas. São Paulo: Loyola, 2007, p. 15-36.

HELLER, Agnes. O Cotidiano e a história. Rio de Janeiro: Paz e Terra, 1972.

HELLER, Agnes. Sociologia de la vida cotidiana. Prefácio de Gyorgy Lukacs. Barcelona: Peninsula, 1991.

HELLER, Agnes. Para mudar de vida: felicidade, liberdade e democracia. Entrevista a Ferdinando Adornato. São Paulo: Brasiliense, 1982. 